\title{
A review on metabolites and pharmaceutical potential of food legume crop mung bean (Vigna radiata L. Wilczek)
}

\author{
Nikhil Mehta, Priyanka Rao, Raman Saini * \\ Department of Biotechnology, Kurukshetra University, Kurukshetra, India
}

\begin{abstract}
Mung bean or moong or green gram, an important grain legume, is cultivated mainly in Asian countries and other parts of the world as a food crop. It is a highly nutritious grain legume with a high content of easily digestible proteins $(20-32 \%)$, carbohydrates (53.3-67.1\%), lipids (0.71-1.85\%), vitamins, minerals, and fiber. It also contains some antinutrients such as tannins, phytic acid, hemagglutinin, polyphenols, and trypsin inhibitors in low concentrations. The sprouting of seeds leads to dynamic changes in metabolites with a decrease in antinutrient content and an increase in the nutritional value. In addition to these nutrients and antinutrients, the plant also contains various other phytochemicals such as alkaloids, flavonoids, saponins, phenols, glycosides, and bioactive peptides, which exhibit an array of pharmaceutically important properties such as anti-inflammatory, antinociceptive, antimicrobial, antioxidant, antidiabetic, lipid metabolism regulation, antihypertensive, antiallergic, and antitumor. Being rich in nutritional value and other phytochemical components, the plant can be explored further for its pharmaceutical properties and used as an efficient food additive in the preparation of different types of dietary supplements or food-derived drugs.
\end{abstract}

Key words: bioactivity, medicinal property, metabolites, mung bean, nutritional value, phytochemicals

\section{Introduction}

With an increase in clinical evidence showing the health benefits of plant-derived foods, there has been an increase in the consumption of these foods (Alcorta et al., 2021). Plant-derived foods are also recommended by many health organizations such as WHO because of their benefits in the prevention of chronic diseases and improvement of health status (Hou et al., 2019). Mung bean is grown and consumed mainly in Asia, but since recently, it has also been cultivated in other parts of the world and consumed worldwide in the form of seeds (intact or processed) and sprouts (Schafleitner et al., 2015). Mung bean seeds are plant-derived food with several health beneficial properties: it is used as a mood refresher in summer, and it reduces swelling and helps in elimination of toxins from the body. Nutritionally, mung bean is a balanced food that contains proteins and fibers along with bioactive phytochemicals. High levels of oligosaccharides and polyphenols in mung bean con- tribute to various pharmaceutical properties such as anti-inflammatory, antimicrobial, antioxidant, lipid metabolism regulation, and antitumor effects (Hou et al., 2019). Seeds of mung bean are used in various forms such as intact or split, fermented, or processed in different ways to make soup, curries, porridge, confections, alcoholic beverages, and flour in various recipes. Mung bean contains a high content of proteins (20-32\%), of which approximately $60 \%$ and $25 \%$ are two storage proteins, namely globulin and albumin, respectively, along with essential amino acids (Mubarak, 2005). Mung bean consumption is also beneficial for individuals with diabetes and obesity as it yields lower energy upon digestion because of the high content of proteins (Yao et al., 2013). Mung bean also contains phytochemicals such as tannins, trypsin inhibitors, hemagglutinin, and phytic acid, which play a role in biological activities like promotion of digestion and elimination of toxins from the body (Hou et al., 2019). Consistent eating of mung

\footnotetext{
* Corresponding author: Department of Biotechnology, Kurukshetra University, Kurukshetra, India; e-mail: ramanksaini@rediffmail.com
} 
bean helps to regulate the Enterobacteriaceae flora in the intestine; to decrease the risk of coronary heart disease, hypercholesterolemia, and cancer; and to reduce the absorption of toxic substances (Kruawan et al., 2012; Novidiyanto et al., 2016; Lopes et al., 2018). In the context to the abovementioned views, the present study enlightens various aspects of mung bean such as its nutritional values, metabolites, and pharmaceutical properties to signify its nourishing importance for the betterment of humans. The information on the metabolites and pharmaceutical properties of mung bean could be used in the future to further explore mung bean in the preparation of various nutraceuticals, drugs, or preventive agents in a crude or pure form of active metabolites for various human disorders.

\section{Metabolites}

\section{Nutritional value}

Mung bean is primarily grown for its edible seeds that are rich in easily digestible proteins and a good amount of phosphorus and provitamin A (Vir et al., 2018). Various studies conducted using different varieties obtained from different geographical locations have revealed that seeds of mung bean contain moisture (4.10-15.20\%), crude proteins $(20-32 \%)$, crude lipids $(0.71-1.85 \%)$, crude fibers (3.8-6.15\%), ash (0.17-5.87\%), and carbohydrates (53.3-67.1\%), along with vitamins and minerals (Dahiya et al., 2015). The lipid content of the seed coat has higher amounts of unsaturated fatty acids $(72.8 \%$ of total lipid content) that include oleic (20.8\%), linoleic (16.3\%), and linolenic acids (35.7\%). The saturated fatty acid content is $27.7 \%$ and comprises $14.1 \%$ palmitic acid, $4.3 \%$ stearic acid, and 9.3\% behenic acid (Dahiya et al., 2015). Mung bean oil also contains vitamin E, including tocopherols and tocotrienol. Other vitamins present in mung bean are thiamine, riboflavin, vitamin $\mathrm{C}$, pantothenic acid, and nicotinic acid. Mung bean seeds contain good amounts of minerals such as calcium, potassium, magnesium, and phytin phosphorus. Minerals such as copper, iron, manganese, sodium, and zinc are also present in the bean seeds. Apart from these, some antinutritional factors are present in mung bean seeds, including tannins, phytic acid, hemagglutinin, polyphenols, and trypsin inhibitors (Ganesan and Xu, 2018; Shen et al., 2018) (Table 1). Although the amount of these antinutritional components is very low in seeds, they may hinder the
Table 1. Nutritional value of the mungbean seeds

\begin{tabular}{|c|c|}
\hline Component & $\begin{array}{l}\text { Content per } 100 \mathrm{~g} \\
\text { mungbean seeds }\end{array}$ \\
\hline Protein & $22.9 \mathrm{~g}$ \\
\hline Fats & $1.2 \mathrm{~g}$ \\
\hline Carbohydrate & $61.8 \mathrm{~g}$ \\
\hline Starch & $43.6 \mathrm{~g}$ \\
\hline Amylase & $13.8 \mathrm{~g}$ \\
\hline Sucrose & $0.3 \mathrm{~g}$ \\
\hline Raffinose & $0.3 \mathrm{~g}$ \\
\hline Stachyose & $1.2 \mathrm{~g}$ \\
\hline Verbascose & $1.7 \mathrm{~g}$ \\
\hline Lignin & $2.5 \mathrm{~g}$ \\
\hline Cellulose & $0.3 \mathrm{~g}$ \\
\hline Fibre & $4.4 \mathrm{~g}$ \\
\hline Ash & $3.5 \mathrm{~g}$ \\
\hline Carotene & $94 \mu \mathrm{g}$ \\
\hline Folic acid & $140 \mu \mathrm{g}$ \\
\hline Niacin & $2.1 \mathrm{mg}$ \\
\hline Riboflavin & $0.27 \mathrm{mg}$ \\
\hline Thiamine & $0.47 \mathrm{mg}$ \\
\hline Calcium & $124 \mathrm{mg}$ \\
\hline Copper & $0.97 \mathrm{mg}$ \\
\hline Iron & $7.3 \mathrm{mg}$ \\
\hline Magnesium & $171 \mathrm{mg}$ \\
\hline Phosphorus & $326 \mathrm{mg}$ \\
\hline Potassium & $843 \mathrm{mg}$ \\
\hline Sodium & $28 \mathrm{mg}$ \\
\hline Trypsin inhibitor & $64 \mathrm{U}$ \\
\hline Subtilisin inhibitor & $35 \mathrm{U}$ \\
\hline Tannins & $437 \mathrm{mg}$ \\
\hline Phytates & $670 \mathrm{mg}$ \\
\hline
\end{tabular}

nutritional uptake from the seeds. Phytic acid in particular hinders the uptake of iron and zinc in plant-based diets (Hou et al., 2019). Sprouting of seeds has been reported to reduce the antinutritional content of the seeds and to increase its digestibility and nutritional uptake (Tang et al., 2014). Upon germination, $30.24-58.97 \%$ of phytic acid is reported to be hydrolyzed. Apart from germination, other methods to reduce the level of activity of these antinutritional components are soaking and boiling mung bean seeds prior to consumption (Samtiya 
et al., 2020). Water-soluble components such as raffinose can be removed to a significant extent by discarding the soak water, resulting in the hydrolysis of $93.62 \%$ of raffinose (Tang et al., 2014). In combination with cereals such as wheat and rice, mung bean forms a balanced amino acid profile with its high protein levels (19-29\%), with high lysine/low methionine amino acid profile of mung bean complementing the low lysine/high methionine and high carbohydrate content of cereals (Vir et al., 2016). This has led to the use of mung bean as baby food because of its rich content of easily digestible proteins, vitamins, and iron (Hou et al., 2019).

Mung bean seeds and sprouts contain different components such as organic acids (citric acid, phosphoric acid), phenolic acids, lipids ( $\gamma$-tocopherol), and flavonoids that have been recognized to contribute to the pharmaceutical properties (Hou et al., 2019). Different compounds have been isolated from mung bean that belongs to different classes such as flavones, isoflavones, flavonoids, and isoflavonoids (Prokudina et al., 2012). Most of these compounds have been classified as polyphenols because of their polyhydroxy substitutions and were shown to possess antioxidant activity. Vitexin and isovitexin have been reported to be the most abundant flavones present at the concentration of 51.1 and $1.7 \mathrm{mg} / \mathrm{g}$, respectively (Li et al., 2012). Apart from antioxidant activity, these flavonoids are involved in many other plant activities such as early plant development and signaling and protection from stress, insects, and mammalian herbivores (Ganesan and $\mathrm{Xu}$, 2018).

\section{Effect of sprouting on dynamic changes in the metabolite content of mung bean}

Different studies have shown that upon germination of mung bean, dynamic changes occur in the concentration of metabolites. These changes involve decrease in the concentration of antinutrient components and a significant increase in the free amino acid concentrations along with increased levels of thiamine, riboflavin, niacin, and ascorbic acid, which is favored worldwide and mostly in Asia and North America (Tang et al., 2014). The amount of vitamin C increases up to $1380 \mathrm{mg} / \mathrm{kg}$ in sprouts as compared to $50 \mathrm{mg} / \mathrm{kg}$ in mung bean dry seeds, thus enhancing iron absorption (Guo et al., 2012). Moreover, the level of reducing sugars and starch reduced significantly with the complete elimination of sta- chyose and raffinose (Guo et al., 2012). There is a dramatic increase in the concentrations of gallic acid, chlorogenic acid, and coumarin throughout the sprouting process, whereas the catechin level increases at the end of sprouting (Tang et al., 2014). Some phenolic acids such as cinnamic acid, gentisic acid, and p-hydroxybenzoic acid remain present throughout the process of sprouting (Amarowicz et al., 2009). A trans-esterification reaction also occurs that converts crude lipids into fatty acid methyl esters and triglycerides. The $\gamma$-aminobutyric acid level is enhanced throughout the sprouting process, which is important as it has several health benefits (Moumita et al., 2010). Other pharmaceutically important proteins reported in mung bean are protease inhibitors that have the property to inhibit the proteolytic enzymes and thus regulate proteolytic processes that play a major role in the defense system of plants against different pathogenic organisms (Tang et al., 2014). The level of trypsin inhibitors decreases gradually during germination. The activity of hemagglutinin has been found to decrease by approximately $4 \%$ during the germination process (Tang et al., 2014).

\section{Pharmaceutical properties of mung bean}

The detoxification activity of mung bean is well known from ancient times and is thought to be contributed by proteins, tannins, and other polyphenols that help in the excretion of heavy metals such as arsenic, mercury, and organophosphorus pesticides by forming sediments with them (Hou et al., 2019). Other biological activities of mung bean have also been reported such as antioxidant, antimicrobial, anti-inflammatory, immunomodulatory or anti-allergic, antidiabetic, lipid metabolism modulator, antihypertensive, antitumor, hepatoprotective, antinociceptive, and alcohol dehydrogenase and tyrosinase inhibition activity, which show its potential for use as an alternative for prescribed drugs or as a preventive agent for various human ailments (Kim et al., 2012). Some of the properties of mung bean have been discussed below (Table 2).

\section{Antioxidant effects}

Mung bean seeds, sprouts, and even hulls have been shown to possess antioxidant activity. The methanolic extracts of mung bean exhibit high free radical scavenging and reducing power activity because of the pre- 
Table 2. Different biological activities shown by mungbean

\begin{tabular}{l|l}
\hline \multicolumn{1}{c|}{ Biological activities } & \multicolumn{1}{c}{ Biological compounds } \\
\hline Antioxidant effects & $\begin{array}{l}\text { proteins, polypeptides, } \\
\text { polysaccharides, polyphenols }\end{array}$ \\
\hline Antimicrobial activity & peptides, polyphenols \\
\hline Anti-inflammatory activity & polyphenols \\
\hline Antidiabetic activity & polyphenols \\
\hline Lipid metabolism accommodation & phytosterol \\
\hline Antihypertensive effects & proteins \\
\hline Antitumor effects & polyphenols, trypsin inhibitor fragments \\
\hline Antisepsis effects & polyphenols, aqueous extracts \\
\hline Hepatoprotective & polyphenols \\
\hline
\end{tabular}

sence of a high level of polyphenols (Ganesan and $\mathrm{Xu}$, 2018). Moreover, acetone extracts from sprouts show higher activity than the extracts from seeds because of the occurrence of a higher amount of total phenols and flavonoids (4.5 and 6.8 times more, respectively) than raw seeds (Guo et al., 2012; Paja et al., 2014). The free radical scavenging activity of mung bean seeds' soup was compared with that of green tea and vitamin $\mathrm{C}$, and it was found that $100 \mathrm{~g}$ of mung bean, $36.3 \mathrm{~g}$ of dried tea, and $1462 \mathrm{mg}$ of vitamin $\mathrm{C}$ showed equivalent level of free radical scavenging activity (Cao et al., 2011). This high antioxidant activity is due to the presence of two major antioxidant compounds, namely vitexin and isovitexin, among which vitexin alone is capable of inhibiting DPPH radicals by approximately $60 \%$ at the concentration of $100 \mu \mathrm{g} / \mathrm{ml}$ and was found to be effective in preventing cell death from UV-induced skin damage (Cao et al., 2011). Methanolic extracts of seed coats (obtained from sprouted seeds) were shown to possess high antioxidant potential ( $80 \%$ and $77 \%$ ) at the concentration of $100 \mu \mathrm{g} / \mathrm{ml}$ when tested by DPPH (2,2-diphenyl-1-picrylhydrazyl) and FRAP (Ferric Reducing Antioxidant Power) methods, respectively (Mehta et al., 2021).

\section{Antimicrobial activity}

Biocides or phytochemicals with antimicrobial activity are gaining popularity because of their broad-spectrum activity with no known side effects. Several reports have been published showing the potential of mung bean as an antimicrobial agent (Tang et al., 2014; Ganesan and $\mathrm{Xu}, 2018$; Shen et al., 2018; Mehta et al., 2021) (Table 3). A nonspecific lipid transfer peptide (nsLTP; molecular weight: $9.03 \mathrm{kDa}$ ) that shows broad-spectrum antibacterial and antifungal activity has been isolated from mung bean (Shen et al., 2018). It is active against fungi such as Fusarium oxysporum, F. solani, Pythium aphanidermatum, and Sclerotium rolfsii along with the bacterial species Staphylococcus aureus. A cyclophilinlike antifungal protein "mungin" has been isolated from the aqueous extract of seeds that exhibits inhibitory activity against $\alpha$ - and $\beta$-glucosidases and shows antifungal activity against fungi such as Rhizoctonia solani, Mycosphaerella arachidicola, Coprinus comatus, Botrytis cinerea, and Fusarium oxysporum (Shen et al., 2018). Chitinase has also been isolated from aqueous extracts of mung bean seeds with a specific activity of $3.81 \mathrm{U} / \mathrm{mg}$ and $\mathrm{pI}$ of 6.3 , and it shows antifungal activity against Fusarium oxysporum, Rhizoctonia solani, Mycosphaerella arachidicola, Pythium aphanidermatum, and Sclerotium rolfsii (Tang et al., 2014). The polyphenol extract from the sprouts exhibited antibacterial properties against Helicobacter pylori, which causes gastro-duodenal diseases in humans (Tang et al., 2014). Recently, methanolic extracts of mung bean seed coat have been shown to exhibit broad-spectrum antibacterial activity against Bacillus cereus, Bacillus subtilis, Escherichia coli, Klebsiella pneumoniae, Pseudomonas aeruginosa, and $S$. aureus (Mehta et al., 2021).

\section{Anti-inflammatory and immunomodulatory activity}

Inflammation may occur because of several causes such as infection, foreign body stimulus, and tissue damage and has been associated with nitric oxide and proin ammatory cytokines produced by the activation of the 
Table 3. Antimicrobial activity of the mungbean against different tested microorganisms *

\begin{tabular}{l|l}
\hline \multicolumn{1}{c}{ Mungbean extract/compound tested } & \multicolumn{1}{c}{ Tested microorganism } \\
\hline Lipid transfer peptide & $\begin{array}{l}\text { Fusarium oxysporum, F. solani, Pythium aphanidermatum, } \\
\text { Sclerotium rolfsii, Staphylococcus aureus }\end{array}$ \\
\hline Mungin & $\begin{array}{l}\text { Rhizoctonia solani, Mycosphaerella arachidicola, Coprinus comatus, } \\
\text { Botrytus cinera, and Fusarium oxysporum }\end{array}$ \\
\hline Chitinase & $\begin{array}{l}\text { Fusarium oxysporum, Rhizoctonia solani, Mycosphaerella arachidicola, } \\
\text { Pythium aphanidermatum, and Sclerotium rolfsii }\end{array}$ \\
\hline Sprout polyphenol extract & Helicobacter pylori \\
\hline Seed coat methanolic extract & $\begin{array}{l}\text { Bacillus cereus, Bacillus subtilis, Escherichia coli, Klebsiella pneumoniae, } \\
\text { Pseudomonas aeruginosa, and Staphylococcus aureus }\end{array}$ \\
\hline
\end{tabular}

* Tang et al., 2014; Ganesan and Xu, 2018; Shen et al., 2018; Mehta et al., 2021

immune system (Ali et al., 2014; Soufli et al., 2016). Mung bean has been found to be beneficial for treating various inflammatory responses, and this is evident from its use in folk remedies and cuisine, particularly in Asian countries (Lee et al., 2011). Clinical evidence of the antiinflammatory activity was obtained by analyzing the effect of the ethanolic extract of mung bean on lipopolysaccharide-stimulated macrophages. The study showed a noncytotoxic decrease in macrophage activity through the suppression of pro-inflammatory genes such as Apoe and Bcl2a1a (Yeap et al., 2012). This activity was found to be associated with the presence of polyphenols, vitexin, isovitexin, and gallic acid in the extract. In another study, treatment of cells with the polyphenol fraction $(3.7 \mathrm{mg} / \mathrm{ml})$ of ethanolic extract of mung bean seeds was shown to drastically downregulate pro-inflammatory cytokines such as IL-6, IL- $1 \beta$, IL-12 $\beta$, TNF- $\alpha$, and inducible NO synthase (Lee et al., 2011). The anti-inflammatory response was also shown by aqueous extracts obtained from germinated and fermented mung bean seeds when dose-dependently tested under in vitro (measured by inhibition of nitric oxide level in cultured cell supernatant) and in vivo (inhibition of arachidonic acid-induced ear edema in mice) conditions (Ali et al., 2014). The in vitro study revealed a decrease in NO level up to 21.6 and $40.3 \%$ for germinated and fermented seed extracts, respectively, while in the in vivo study, both the extracts when used at the concentration of $1000 \mathrm{mg} / \mathrm{kg}$ body weight led to a significant reduction in edema (Ali et al., 2014). Likewise, anti-inflammatory effect of mung bean has also been shown by other researchers either by blocking The cell proliferation and stabilizing $\mathrm{p} 27^{\mathrm{KIP} 1}$ in
Th cells after antigenic stimulation (Lee et al., 2013) or by suppressing LPS-induced IL-1b mRNA expression that leads to a reduced inflammatory response (Zhang et al., 2013). In another study, mung bean was shown to stabilize the liposomal membrane, which prevented the extracellular release of the lysosomal components and thus inhibited an inflammatory response (Venkateshwarlu et al., 2016). Other studies have shown a 30\% decrease in triacylglycerol and total cholesterol levels in the muscle, which was correlated with the suppression of lipogenic genes such as ACC, C/EBP alpha, PGC-1 alpha, and PPAR gamma, subsequently leading to decreased inflammatory response (Inhae et al., 2015). Thus, these results suggest the potential use of mung bean in the reduction of symptoms of inflammatory diseases such as diabetes, allergies, rheumatoid arthritis, autoimmune disease, asthma, cancer, and other inflammatory disorders (Bellik et al., 2012). The aqueous extracts of mung bean also exhibited immunomodulatory activity as evaluated by the BrdU (bromodeoxyuridine) immunoassay, and it was found that $20 \mu \mathrm{g} / \mathrm{ml}$ of phytic acid, genistein, and syringic acid significantly suppressed interleukin-10 secretion and promoted interferon- $\gamma$ secretion, thereby inducing Th-1 (helper T lymphocytes)predominant response (Cherng et al., 2007). Thus, it can be concluded that the non-nutritional components of the mung bean play an important role in human immune modulation. The antiallergic activity of mung bean sprout extracts was also determined by assaying mast cell degranulation and histamine release, and passive cutaneous anaphylaxis (PCA) reaction. The study concluded that flavonoids (kaempferol-3-O-rutinoside, isovitexin, 
and isoquercitrin) of mung bean play a major role in antiallergic activity (Li et al., 2016).

\section{Antidiabetic effects}

Mung bean seeds or sprouts were found to have a significant effect on patients with diabetes. The oral feeding of seeds and ethanolic extracts of sprouts to type 2 diabetic mice lowered their blood glucose level and affected the level of plasma C-peptide, triglycerides, total cholesterol, blood urea nitrogen, and glucagon. Moreover, there was a marked improvement in insulin immunoreactive levels and increased glucose tolerance (Ganesan and $\mathrm{Xu}, 2018)$. The ethanolic extracts of sprouts were more effective in controlling high sugar levels because of their high content of starch-hydrolyzing enzymes ( $\alpha$-amylase and $\alpha$-glycosidase) inhibitors. This inhibition potential of extracts has correlation with high phenolic content that reduced the intestinal absorption of carbohydrates and eventually lowered the blood glucose level (Randhir and Shetty, 2007; Yao et al., 2013; Luo et al., 2016). Randhir and Shetty (2007) reported that $\alpha$-amylase and Helicobacter pylorigrowth inhibition were related to diabetic management and peptic ulcer management, respectively. Diabetic conditions were also associated with enhancement in the production of reactive oxygen species (ROS) that caused malfunction of $\beta$-cells and enhanced resistance to insulin, which further promoted type 2 diabetes (Ganesan and $\mathrm{Xu}, 2018$ ). In this context, a study revealed that the phenolic compounds and flavonoids of mung bean lowered the formation of ROS and showed scavenging activity against free radicals, thus modulating hyperglycemia (Yeap et al., 2012). Furthermore, mung bean starch containing $32 \%$ amylose was considered to lower glycemia and thus help in glucose metabolism in persons with diabetes (Ren et al., 2015).

\section{Lipid metabolism modulator activity}

Various experimental studies (in vitro or animal experiments) showed that feeding mung bean in any form (extract/powdered/fermented or other approach) improved lipid metabolism (Tang et al., 2014; Yeap et al., 2015; Asrullah et al., 2016; Lopes et al., 2018; Liu et al., 2019). According to these studies, mung bean constituents (proteins, phenolics, and flavonoids) dose-dependently decreased blood total cholesterol, triglyceride, and low-density lipoprotein (LDL) levels and increased high-density lipid levels. A study involving rats and mice showed a significant decline in cholesterol level; this decline was thought to be due to the presence of cholesterol-like compounds such as phytosterol in mung bean, which prevented the synthesis and absorption of cholesterol (Asrullah et al., 2016). In a study by Yao et al. (2014), mung bean exhibited total cholesterol reducing property as shown by increased fecal excretion of sterol and bile acids and decline in intestinal uptake and synthesis of cholesterol. In another in vitro and animal study, ethanolic extracts and flavonoids (vitexin and isovitexin) of mung bean significantly lowered fat accumulation by decreasing the expression of genes involved in lipogenesis such as enzyme acetyl-CoA carboxylase (which involved in fatty acid synthesis), peroxisome proliferator-activated receptor-ligand-activated transcription factors (enhancing fatty acid storage), and the CCAAT/ enhancer-binding protein which act as a fat metabolismregulating transcriptional factor. (Inhae et al., 2015). Mung bean starch and fiber fermentation by gut microflora has been reported to yield high content of shortchain fatty acids that reduced the levels of total cholesterol, LDL, and triglycerides in blood plasma (London et al., 2014; Reverri et al., 2017). Antioxidants of mung bean have also been shown to exert a hypolipidemic effect on hypercholesterolemic mice (Yeap et al., 2015; Liu et al., 2019).

\section{Antihypertensive effect}

Among the synthetic drugs used to regulate blood pressure, angiotensin-converting enzyme (ACE) inhibitors play an important role (Sonklin et al., 2020). In this context, mung bean was also found to affect the renin angiotensin system through its ACE inhibitor peptides. This resulted in lowering of the ACE enzyme activity and reduced the conversion of plasma angiotensin-I into angiotensin-II, wherein the latter one is involved in increasing blood pressure by acting directly on blood vessels, sympathetic nerves, and adrenal glands ( $\mathrm{Li}$ et al., 2005; Xie et al., 2019; Sonklin et al., 2020). The resultant inhibition led to the control of hypertension. In some studies, by using sprout powder, juice, and concentrated extracts, it was found that the systolic blood pressure reduced significantly in short-term (3-6 h) and long-term (30 days) studies in rats; thus, mung bean showed potential in the prevention and management of hypertension (Hsu et al., 2011; Sonklin et al., 2020). 


\section{Antitumor effects}

Although the precise mechanisms that regulate the prevention of cancer are fully recognized, several studies have proved that mung bean exerts antitumor effects through different mechanisms of action. One of these mechanisms is the action of nucleases R-TBN1 and R-HBN1 present in mung bean that were effective against the human myeloblastic leukemia cell line ML-2 (Matousek et al., 2009). These plant-derived nucleases were reported to be 10 times more potent than the bovine seminal ribonuclease and less toxic with high efficiency and stability for use as a biochemical agent for antitumor or cytostatic effect (Matousek et al., 2009). Mung bean also showed dose-dependent antiproliferative effect as determined by the MTT assay against various cancer cell lines such as tongue squamous cell carcinoma cell line (CAL27), prostate cancer cell line (DU145), breast cancer cell line (MCF-7), blood cancer cell line (HL-60), and ovary cancer cell line (SK-OV-3) (Xu and Chang, 2012). Another mechanism of action of mung bean was through trypsin inhibitors that affected the proliferation and metastasis of human colon cancer cells (SW480). The effect was confirmed through the wound healing assay in which the effect of a purified active peptide fragment of trypsin inhibitor was tested on a cancer cell line, and it was found that the concentration of $10 \mu \mathrm{mol} / 1$ effectively exhibited wound healing property with $50 \%$ reduction as compared to control (Zhao et al., 2012). In another study, acidified methanol extracts of sprouted mung bean were shown to induce apoptosis and cell cycle arrest/slowdown. This study concluded that the Cdk-inhibitor proteins ( $221, \mathrm{p} 27$, and $\mathrm{p} 53$ ), TNF- $\alpha$, and interferon- $\beta$ (IFN- $\beta$ ) may be the key regulatory factors responsible for this regulation ( $\mathrm{Ha} \mathrm{dh}$ et al., 2012). In another study, fermented mung bean extract (aqueous) was shown to halt the progression of breast cancer by decreasing the mitotic division of tumor cells through the promotion of IL-2 and IFN- $\gamma$ production and cytotoxicity (Yeap et al., 2013). The components of mung bean, mainly starch, dietary fibers, phenolic compounds, and microconstituents such as phytic acid, vitexin, isovitexin, protease inhibitors, and saponins, have been shown to possess antioxidant and anticarcinogenic properties in various in vitro and animal studies (Hangen and Bennink, 2003; Patterson et al., 2009; Makhafola et al., 2016; Alam et al., 2017; Barahuie et al., 2017; Park et., 2017). Recently, by performing SRB (Sulforhodamine
B) assay, methanolic extracts of seed coat (obtained from sprouted seeds) were shown to exhibit anticancer activity against the human lung cancer cell line HOP-62; the extract at $80 \mu \mathrm{g} / \mathrm{ml}$ concentration showed $65 \%$ cell growth inhibition activity (Mehta et al., 2021).

\section{Hepatoprotective activity}

The liver acts as a vital organ in the process of metabolism, storage, and excretion of various metabolites, and its dysfunction is associated with various ailments such as direct hepatic damage, inflammation, and fibrosis (Alshammari et al., 2018; Lopes et al., 2018). Consumption of mung bean in different forms such as sprouted, cooked, or fermented beans has been shown to exhibit significant hepatoprotective activity in a dose-dependent manner by decreasing enzyme activities (asparagine aminotransferase and alanine aminotransferase) and preventing excess deposition of fat (Lopes et al., 2018). The occurrence of nonalcoholic fatty liver disease is promoted by oxidative stress and ROS; in this context, mung bean was shown to overcome oxidative stress, lower the formation of ROS, and increase scavenging activity against free radicals (Yeap et al., 2012; Golabi et al., 2017; Alshammari et al., 2018). In alcohol-induced liver injury, aqueous extracts of mung bean were shown to significantly decline the serum level of enzymes (alanine aminotransferase and aspartate aminotransferase), total cholesterol, triglyceride, nitric oxide, and malondialdehyde and increase FRAP and superoxide dismutase activities (Ali et al., 2013). In another study involving an alcohol-induced liver injury (mouse) model, flavonoids were shown to exhibit significant hepatoprotective activity because of their antioxidant potential and through suppression of hepatic lipid accumulation (Liu et al., 2015).

\section{Other biological properties}

In addition to the above mentioned activities, mung bean also possesses other biological properties that might be significant for human health. These include antinociceptive effect (pain-relieving), where mung bean extracts inhibited the production of nitric oxide, a potent pain mediator (Ali et al., 2014); detoxification activity, where mung bean polyphenol extracts prevented cardiovascular diseases by acting against Al-induced biotoxicity through the ROS-JNK and NF-kB-mediated caspase pathways (Cheng et al., 2017); and alcohol dehydrogenase 
and tyrosinase inhibition activity, where the ethyl acetate extracts of mung bean showed activity against melanogenesis and thus could be used in cosmetics (Jeong et al., 2016).

\section{Conclusions}

Apart from the nutritional benefits, mung bean possesses various phytochemicals with an array of biological properties that can benefit human health. Dynamic changes occur in mung bean on sprouting that result in an increase in concentrations of various metabolites, which significantly enhance its biological properties. In addition to sprouting, the processing of mung bean through diverse methods such as thermal treatment, fermentation, and enzymatic or chemical hydrolysis of the whole powered content or its proteins and aqueous or other solvent extracts have been reported to promote and alter various biological properties in several studies. Various studies (in vitro or in vivo) reported in the current review support the conclusion that mung bean exhibits several pharmaceutically important properties such as antimicrobial, antioxidant, anti-inflammatory, immunomodulatory or antiallergic, antidiabetic, lipid metabolism modulator, antihypertensive, antitumor, hepatoprotective, antinociceptive, and alcohol dehydrogenase and tyrosinase inhibition activity. However, to date, most studies have been conducted using the crude extracts (aqueous or organic) of processed or nonprocessed mung bean and thus have some lacunae related to the active metabolite with specific biological property along with less knowledge of the precise mechanism of action in several properties. Although several studies have reported flavonoids such as vitexin and isovitexin and peptides are the principal active components that regulate the biological properties, a majority of other principle active components with biological properties are yet to be identified. This opens up avenues of further research to reveal other functional components of mung bean relevant to the biological properties, mechanism of their action, exploration of other hidden health benefit potential, and focus on the importance of the multimetabolite co-active effects on biological properties. Overall, on the basis of the studies conducted on mung bean, it can be concluded that the consumption of native mung bean seeds or in any processed form is significant for human health and that these seeds could be used in the preparation of various nutraceuticals and baby food and as an alternative for prescribed synthetic drugs or as a preventive agent for various human disorders.

\section{References}

Alam F., Saqib Q.N., Waheed A. (2017) Cytotoxic activity of extracts and crude saponins from Zanthoxylum armatum DC. against human breast (MCF-7, MDA-MB-468) and colorectal (Caco-2) cancer cell lines. BMC Complement. Altern. Med. 17(1): 1-9. https://doi.org/10.1186/s12906017-1882-1.

Alcorta A., Porta A., Tárrega A., Alvarez M.D., Vaquero M.P. (2021) Foods for plant-based diets: challenges and innovations. Foods (Basel, Switzerland), 10(2): 293. https:// doi.org/10.3390/foods10020293.

Ali N.M., Yusof H.M., Long K., Yeap S.K., Ho W.Y., Beh B.K., Koh S.P., Abdullah M.P., Alitheen N.B. (2013) Antioxidant and hepatoprotective effect of aqueous extract of germinated and fermented mung bean on ethanol-mediated liver damage. BioMed. Res. Int. 13: 693613. https://doi.org/ $10.1155 / 2013 / 693613$.

Ali N.M., Yusof H.M., Yeap S., Ho W., Beh B., Long K., Koh S., Abdullah M.P., Alitheen N.B. (2014) Anti-Inflammatory and antinociceptive activities of untreated, germinated, and fermented mung bean aqueous extract. Evid-Based Complement. Altern. Med. 350507. https://doi.org/10.1155/2014/ 350507.

Alshammari G.M., Balakrishnan A., Chinnasamy T. (2018) Protective role of germinated mung bean against progression of non-alcoholic steatohepatitis in rats: a dietary therapy to improve fatty liver health. J. Food Biochem. 42: e12542. https://doi.org/10.1111/jfbc.12542.

Amarowicz R., Żegarska Z., Rafałowski R., Pegg R.B., Karamać M., Kosińska A. (2009) Antioxidant activity and free radical scavenging capacity of ethanolic extracts of thyme, oregano, and marjoram. Eur. J. Lipid Sci. Technol. 111(11): 1111-1117. https://doi.org/10.1002/ejlt.200800170.

Asrullah M., Lestari L.A., Helmyati S., Farmawati A. (2016) The effect of mung bean sprouts (Phaseolus radiatus L.) to lipid profile of male Sprague Dawley rats fed with high-fat diet. AIP Conference Proceedings 1755: 140001. https:// doi.org/10.1063/1.4958562.

Barahuie F., Dorniani D., Saifullah B., Gothai S., Hussein M.Z., Pandurangan A.K., Arulselvan P., Norhaizan M.E. (2017) Sustained release of anti-cancer agent phytic acid from its chitosan-coated magnetic nanoparticles for drugdelivery system. Int. J. Nanomedicine. 12: 2361-2372. https://doi.org/10.2147/IJN.S126245.

Bellik Y., Hammoudi S., Abdellah F., Iguer-Ouada M., Boukraa L. (2012) Phytochemicals to prevent inflammation and allergy. Recent Pat. Inflamm. Allergy Drug Discov. 6(2): 147-158. https://doi.org/10.2174/187221312800166886.

Bennink M.R. (2003) Consumption of black beans and navy beans (Phaseolus vulgaris) reduced azoxymethane-induced 
colon cancer in rats. Nutr. Cancer. 44: 60-65. https:// doi.org/10.1207/S15327914NC441_8.

Cao D., Li H., Yi J., Zhang J., Che H., Cao J., Yang L., Zhu C., Jiang W. (2011) Antioxidant properties of the mung bean flavonoids on alleviating heat stress. PLoS One. 6(6): e21071. https://doi.org/10.1371/journal.pone.0021071.

Cheng D., Wang R., Wang C., Hou L. (2017) Mung bean (Phaseolus radiatus L.) polyphenol extract attenuates aluminum-induced cardiotoxicity through an ros-triggered $\mathrm{Ca} 2+/$ jnk/nf-kb signaling pathway in rats. Food Funct. 8: 851-859. https://doi.org/10.1039/C6FO01817C.

Cherng J.M., Chiang W., Chiang L.C. (2007) Immunomodulatory activities of edible beans and related constituents from soybean. Food Chem. 104(2): 613-618. https:// doi.org/10.1016/j.foodchem.2006.12.011.

Dahiya P.K., Linnemann A.R., Van Boekel M.A.J.S., Khetarpaul N., Grewal R.B., Nout M.J.R. (2015) Mung bean: technological and nutritional potential. Crit. Rev. Food Sci. Nutr. 55(5): 670-688. https://doi.org/10.1080/10408398. 2012.671202 .

Ganesan K., Xu B. (2018) A critical review on phytochemical profile and health promoting effects of mung bean (Vigna radiata). Food Sci. Hum. Wellness, 7(1): 11-33. https:// doi.org/10.1016/j.fshw.2017.11.002.

Golabi P., Bush H., Younossi Z.M. (2017) Treatment strategies for non-alcoholic fatty liver disease and non-alcoholic steatohepatitis. Clin. Liver Dis. 21: 739-753. https:// doi.org/10.1016/j.cld.2017.06.010.

Guo X., Li T., Tang K., Liu R.H. (2012) Effect of germination on phytochemical pro les and antioxidant activity of mung bean sprouts (Vigna radiata). J. Agric. Food Chem. 60: 11050-11055. https://doi.org/10.1021/jf304443u.

Ha dh R.R., Abdulamir A.S., Bakar F.A., Jalilian F.A., Abas F., Sekawi Z. (2012) Novel molecular, cytotoxical and immunological study on promising and selective anticancer activity of mung bean sprouts. BMC Complement. Altern. Med. 12: 208. https://doi.org/10.1186/1472-6882-12-208.

Hou D., Yousaf L., Xue Y., Hu J., Wu J., Hu X., Feng N., Shen Q. (2019) Mung Bean (Vigna radiata L.): Bioactive polyphenols, polysaccharides, peptides, and health benefits. Nutrients. 11: 1238. https://doi.org/10.3390/nu11061238.

Hsu G.S.W., Lu Y.F., Chang S.H., Hsu S.Y. (2011) Antihypertensive effect of mung bean sprout extracts in spontaneously hypertensive rats. J Food Biochem. 35(1): 278-288. https://doi.org/10.1111/j.1745-4514.2010.00381.x.

Inhae K., Seojin C., Joung H.T., Munji C., Hae-Ri W., Won L.B., Myoungsook L. (2015) Effects of mung bean (Vigna radiata $L$.) ethanol extracts decrease proin ammatory cytokine-induced lipogenesis in the kk-ay diabese mouse model. J. Med. Food. 18: 841-849. https://doi.org/10.1089/ jmf.2014.3364.

Jeong Y.M., Ha J.H., Noh G.Y., Park S.N. (2016) Inhibitory effects of mung bean (Vigna radiata L.) seed and sprout extracts on melanogenesis. Food Sci. Biotechnol. 25: 567-573. https://doi.org/10.1007/s10068-016-0079-6.

Kim D.K., Jeong S.C., Gorinstein S., Chon S.U. (2012) Total polyphenols, antioxidant and antiproliferative activities of different extracts in mung bean seeds and sprouts. Plant Foods Hum. Nutr. 67: 71-75. https://doi.org/10.1007/ s11130-011-0273-x.

Kruawan K., Tongyonk L., Kangsadalampai K. (2012) Antimutagenic and comutagenic activities of some legume seeds and their seed coats. J. Med. Plant Res. 6(22): 3845-3851. https://doi.org/10.5897/JMPR12.243.

Lee S.J., Bae J., Kim S., Jeong S., Choi C.Y., Choi S.P., Kim H.S., Jung W.W., Imm J.Y., Kim S.H., Chun T. (2013) Saponins from soy bean and mung bean inhibit the antigen speciffic activation of helper $t$ cells by blocking cell cycle progression. Biotechnol. Lett. 35: 165-173. https:// doi.org/10.1007/s10529-012-1060-y.

Lee S.J., Lee J.H., Lee H.H., Lee S., Kim S.H., Chun T., Imm J.Y. (2011) Effect of mung bean ethanol extract on pro-in ammtory cytokines in Ips stimulated macrophages. Food Sci. Biotechnol. 20: 519-524. https://doi.org/10.1007/ s10068-011-0072-z.

Li G.H., Le G.W., Liu H., Shi Y.H. (2005) Mung-bean protein hydrolysates obtained with alcalase exhibit angiotensin i-converting enzyme inhibitory activity. Food Sci. Technol. Int. 11: 281-287. https://doi.org/10.1177/ 1082013205056781.

Li H., Cao D., Yi J., Cao J., Jiang W. (2012) Identification of the flavonoids in mung bean (Phaseolus radiatus L) soup and their antioxidant activities. Food Chem. 135(4): 2942-2946. https://doi.org/10.1016/j.foodchem.2012. 07.048.

Li L., Li M.H., Ren H.K., Shi Y.J., Dong Y.M. (2016) Antiallergic effects and related active constituents of mung bean (Vigna radiata) sprouts. Food Sci. Biotechnol. 25(2): 553-559. https://doi.org/10.1007/s10068-016-0077-8.

Liu D., Guan Z., Huang K., Li S., Liu J., Yu W., Duan R. (2019) Protective effects of mung bean (Vigna radiata L.) and pea (Pisum sativum L.) against high-fat-induced oxidative stress. Food Sci. Nutr. 7: 4063-4075. https://doi.org/ 10.1002/fsn3.1271.

Liu T., Xiao H.Y., Gao E.Z., Xiao N.L., Li J.S., Hua L.L., Pei W., Yun L.Z., Zhi G.Y. (2015) Hepatoprotective effect of active constituents isolated from mung beans (Phaseolus radiatus L.) in an alcohol-induced liver injury mouse model. J. Food Biochem. 38: 453-459. https://doi.org/ 10.1111/jfbc. 12083.

London L.E., Kumar A.H., Wall R., Casey P.G., O’Sullivan O., Shanahan F., Hill C., Cotter P.D., Fitzgerald G.F., Ross R.P., Caplice N.M., Stanton C. (2014) Exopolysaccharideproducing probiotic Lacto-bacilli reduce serum cholesterol and modify enteric microbiota in ApoE \& HIPHEN; deficient mice. J. Nutr. 144: 1956-1962. https://doi.org/ 10.3945/jn.114.191627.

Lopes L.A.R., Martins M.D.C.D.C., Farias L.M.D., Brito A.K.D.S., Lima G.D.M., Carvalho V.B.L.D., Pereira C.F.D.C., Júnior A.M.C., Saldanha T., Arêas J.A.G. et al., (2018) Cholesterol-lowering and liver-protective effects of cooked and germinated mung beans (Vigna radiata L.). Nutrients 10(7): 821. https://doi.org/10.3390/ nu10070821.

Luo J., Cai W., Wu T., Xu B. (2016) Phytochemical distribution in hull and cotyledon of adzuki bean (Vigna angularis L.) 
and mung bean (Vigna radiata L.), and their contribution to antioxidant, anti-in ammatory and anti-diabetic activities. Food Chem. 201: 350-360. https://doi.org/10.1016/ j.foodchem.2016.01.101.

Makhafola T.J., Elgorashi E.E., McGaw L.J., Verschaeve L., Eloff J.N. (2016) The correlation between antimutagenic activity and total phenolic content of extracts of 31 plant species with high antioxidant activity. BMC Complement. Altern. Med. 16(1): 1-13. https://doi.org/10.1186/s12906016-1437-x.

Matousek J., Podzimek T., Pouckova P., Stehlik J., Skvor J., Soucek J., Matousek J. (2009) Antitumor effects and cytotoxicity of recombinant plant nucleases. Cancer Res. 18(4): 163-171. https://doi.org/10.3727/096504009790217425.

Mehta N., Rao P., Saini R. (2021) Exploration of the antibacterial, antioxidant and anticancer potential of the seed coat extract of mung bean (Vigna radiata $L$. Wilczek). Plant Arch. 21(1): 1628-1633. https://doi.org/10.51470/ PLANT ARCHIVES.2021.v21.no1.222.

Moumita P., Lal B., Mahua G. (2010) Comparative studies on physicochemical and biochemical characteristics of scented and non-scented strains of mung beans (Vigna radiata) of Indian origin. Legum. 33(1): 1-9.

Mubarak A. (2005) Nutritional composition and antinutritional factors of mung bean seeds (Phaseolus aureus) as affected by some home traditional processes. Food Chem. 89: 489-495. https://doi.org/10.1016/j.foodchem.2004.01.007.

Novidiyanto, Asrullah M., Lestari L.A., Helmyati S., Farmawati A. (2019) Effect supplementation of mung bean sprouts (Phaseolus radiatus $L$.) and vitamin $E$ in rats fed high fat diet. [in:] The UGM Annual Scientific Conference Life Sciences 2016, KnE Life Sci: 36-46. https://doi.org/ 10.18502/kls.v4i11.3850.

Pajak K.P., Socha R., Gałkowska D., Roznowski J., Fortuna T. (2014) Phenolic pro le and antioxidant activity in selected seeds and sprouts. Food Chem. 143: 300-306. https:// doi.org/10.1016/j.foodchem.2013.07.064.

Park J.W., Choi W.G., Lee P.J., Chung S.W., Kim B.S., Chung H.T., Cho S., Kim J.H., Kang B.H., Kim H., Kim H.P., Back S.H. (2017) The novel resveratrol derivative 3, 5-diethoxy3', 4-dihydroxy-trans-stilbeneinduces mitochondrial ROS \& HIPHEN; mediated ER stress and cell death in human hepatoma cells in vitro. Acta Pharmacol. Sin. 38: 1486-1500. https://doi.org/10.1038/aps.2017.106.

Patterson C.A., Maskus H., Dupasquier C. (2009) Pulse crops for health. Cereals Foods World 54: 108-113. https:// doi.org/10.1094/CFW-54-3-0108.

Prokudina E., Havlíček L., Al-Maharik N., Lapčík O., Strnad M., Gruz J. (2012) Rapid UPLC-ESI-MS/MS method for the analysis of isoflavonoids and other phenylpropanoids. J. Food Compost. Anal. 26: 36-42. https://doi.org/ 10.1016/ j.jfca.2011.12.001.

Randhir R., Shetty K. (2007) Mung beans processed by solidstate bioconversion improves phenolic content and functionality relevant for diabetes and ulcer management. Innov. Food Sci. Emerg. Technol. 8(2): 197-204. https://doi.org/ 10.1016/j.ifset.2006.10.003.
Ren W., Zhang A.Z., Jiang N., Zhu S., Zhao F.F., Wu Q., Liu W., Wang L.X., Cai P., Wang F.M. (2015) Effects of different amylose to amylopectin ratios on serum indices related to glucose metabolism and glucose transporter expression in fattening lambs. Anim. Feed Sci. Technol. 202: 106-111. https://doi.org/10.1016/j.anifeedsci.2015.02.001.

Reverri E.J., Randolph J.M., Kappagoda C.T., Park E., Edirisinghe I., Burton-Freeman B.M. (2017) Assessing beans as a source of intrinsic fiber onsatiety in men and women with metabolic syndrome. Appetite 118: 75-81. https:// doi.org/10.1016/j.appet.2017.07.013.

Samtiya M., Aluko R.E., Dhewa T. (2020) Plant food antinutritional factors and their reduction strategies: an overview. Food Prod. Process. Nutr. 2(1): 1-14. https:// doi.org/10.1186/s43014-020-0020-5.

Schafleitner R., Nair R.M., Rathore A., Wang Y.W., Lin C.Y., Chu S.H., Ebert A.W. (2015) The AVRDC-The World Vegetable Center mung bean (Vigna radiata) core and mini core collections. BMC Genomics 16(1): 1-11. https:// doi.org/10.1186/s12864-015-1556-7.

Sonklin C., Alashi M.A., Laohakunjit N., Kerdchoechuen O., Aluko R.E. (2020) Identification of antihypertensive peptides from mung bean protein hydrolysate and their effects in spontaneously hypertensive rats. J. Funct. Foods 64: 103635. https://doi.org/10.1016/j.jff.2019.103635.

Soufli I., Toumi R., Rafa H., Touil-Boukoffa, C. (2016) Overview of cytokines and nitric oxide involvement in immunopathogenesis of inflammatory bowel diseases. World J. Gastrointest. Pharmacol. Ther. 7(3): 353. https://doi.org/ 10.4292/wjgpt.v7.i3.353.

Tang D., Dong Y., Ren H., Li L., He C. (2014) A review of phytochemistry, metabolite changes, and medicinal uses of the common food mung bean and its sprouts (Vigna radiata). Chem. Cent. J. 8(1): 1-9. https://doi.org/10.1186/ 1752-153X-8-4.

Venkateshwarlu E., Reddy K.P., Dilip D. (2016) Potential of Vigna radiata (L.) sprouts in the management of in ammation and arthritis in rats: possible biochemical alterations. Ind. J. Exp. Biol. 54: 37-43.

Vir R., Lakhanpaul S., Malik S., Umdale S., Bhat K.V. (2016) Utilization of germplasm for the genetic improvement of mung bean [Vigna radiata (L.) Wilczek]: the constraints and the opportunities. [in:] Gene pool diversity and crop improvement. Springer: 367-391. https://doi.org/ 10.1007/ 978-3-319-27096-8_12.

Xie J., Du M., Shen M., Wu T., Lin L. (2019) Physico-chemical properties, antioxidant activities and angiotensin-i converting enzyme inhibitory of protein hydrolysates from mung bean (Vigna radiata). Food Chem. 270: 243-250. https://doi.org/10.1016/j.foodchem.2018.07.103.

Xu B., Chang S.K. (2012) Comparative study on antiproliferation properties and cellular antioxidant activities of commonly consumed food legumes against nine human cancer cells. Food Chem. 134(3): 1287-1296. https://doi.org/ 10.1016/j.foodchem.2012.02.212.

Yao Y., Hao L., Shi Z., Wang L., Cheng X., Wang S., Ren G. (2014) Mung bean decreases plasma cholesterol by up- 
regulation of cyp7a1. Plant Foods Hum. Nutr. 69: 134-136. https://doi.org/10.1007/s11130-014-0405-1.

Yao Y., Yang X., Tian J., Liu C., Cheng X., Ren G. (2013) Antioxidant and antidiabetic activities of black mung bean (Vigna radiata L.). J. Agric. Food Chem. 61: 8104-8109. https://doi.org/10.1021/jf401812z.

Yeap S.K., Beh B.K., Ho W.Y., Yusof H.M., Mohamad N.E., Ali N.M., Jaganath I.B., Alitheen N.B., Koh S.P., Long K. (2015) In vivo antioxidant and hypolipidemic effects of fermented mung bean on hypercholesterolemic mice. EvidBased Complementary Altern. Med. 508029. https:// doi.org/10.1155/2015/508029.

Yeap S.K., Mohd Ali N., Mohd Yusof H., Alitheen N.B., Beh B.K., Ho W.Y., Koh S.P., Long K. (2012) Antihyperglycemic effects of fermented and nonfermented mung bean extracts on alloxan-induced-diabetic mice. J. Biomed. Biotechnol. 285430. https://doi.org/10.1155/2012/285430.

Yeap S.K., Mohd Yusof H., Mohamad N.E., Beh B.K., Ho W.Y., Ali N.M., Alitheen N.B., Koh S.P., Long K. (2013) In vivo immunomodulation and lipid peroxidation activities contri- buted to chemoprevention e ects of fermented mung bean against breast cancer. Evid-Based Complementary Altern. Med. 13: 708464. https://doi.org/10.1155/2013/708464. Yi-Shen Z., Shuai S., FitzGerald R. (2018) Mung bean proteins and peptides: nutritional, functional and bioactive properties. Food Nutr. Res. 62. https://doi.org/10.29219/fnr. v62.1290.

Zhang X., Shang P., Qin F., Zhou Q., Gao B., Huang H., Yang H., Shi H., Yu L. (2013) Chemical composition and antioxidative and anti-infflammatory properties of ten commercial mung bean samples. LWT-Food Sci. Technol. 54: 171-178. https://doi.org/10.1016/j.lwt.2013.05.034.

Zhao Y.R., Li Z.W., Zhao C., Fu R., Wang X.H., Li Z.Y. (2012) Effects of recombinant mung bean trypsin inhibitor fragments on migration of colon cancer cell SW480. J. Shanxi Uni. (Natural Science Edition), 1: 29. 